\title{
REPREZENTAREA MENTALULUI RELIGIOS ÎN TOPONIMIA ROMÂNEASCĂ
}

\author{
Daniela Butnaru, Ana-Maria Prisacaru \\ Institutul de Filologie „A. Philippide” din Iași, România
}

\section{Illustrations of religious mentality in Romanian toponymy}

\begin{abstract}
In this paper, the authors examine and demonstrate the manner in which naming illustrates the religious imagination of a community who sees and analyzes the concrete representations of objects and names, thus reflecting the natives' attitude towards the designated objects. In Romanian toponymy, some topical names evoke saints and demons or certain religious elements.

Religious apperception is represented in both standard and folk toponymy. Names of settlements (Sântion, Sântana, Adjudul, Onofreiul, Santa Mare, Sfântul Ilie, Chilia, Crucea), passageways (Aleea Sfântul Ioan Iacob Hozevitul, Strada Preot Munteanu Vasile, Str. Patriarh Nicodim Munteanu, Pasajul Sfânta Vineri), squares (Piața Sfântul Anton de Padova, Piața Sfânta Vineri), waterways (Pârâul Schitului) and so on are mostly arbitrary. Nevertheless, there are also official place names resulting from the association of geographical objects with certain biblical characters (Adam şi Eva, 12 Apostoli), sometimes due to the proximity of a place to a religious landmark or establishment. Hardly accessible or dangerous places are frequently accounted for and named after evil characters: Borta Dracului, Gura Iadului, Drăcoaia, Cheile Cornii, Dealul Hicleanului, Moara Dracului etc.

Most of the times such place names are only apparently religious, but they are actually derived from cognomens.
\end{abstract}

Keywords: place names, religious mentality, official, popular, Devil's places.

„Adevărată arhivă” a unui popor (Iordan 1963: 2), toponimia nu conservă doar nume de locuri rezultate în urma observării obiective a realității desemnate, ci și nume care includ în conținutul lor atribute izvorâte prin prisma reflecției (subiective a) denominatorului. Aflat în fața naturii, acesta vede, analizează obiectul geografic concret și îl numește în funcție de caracteristici care îl disting de alte obiecte de acelaşi fel, de proprietari și/sau de cunoștințele și experiențele personale. Domeniul religios este deosebit de ofertant în denominație topică subiectivă, deoarece în numele de locuri care invocă sfinți, demoni sau forțe supranaturale transpar atât credința, cât și superstițiile și temerile oamenilor.

Astfel de reprezentări ale religiozității poporului nostru, uneori foarte plastice, se găsesc mai ales la nivelul microtoponimiei, însă și toponimia majoră numără destule nume topice care au în componență nume de sfinți, de personaje bisericești sau de 
lăcașuri și obiecte de cult. În cadrul celor două categorii, distingem alte două tipuri de denumiri de factură religioasă: toponime populare, apărute în mod spontan și motivate de caracteristici ale obiectului sociogeografic desemnat, și toponime oficiale, stabilite de cele mai multe ori în mod arbitrar de către reprezentanți ai administrației sau geografi.

\section{Toponime majore}

Operând o clasificare a motivelor creștine care apar în toponimia românească, Dragoș Moldovanu remarca preponderența numelor topice care reflectă aspectul social al vieții religioase, componenta spirituală a religiozității fiind reprezentată relativ parcimonios de toponimele amintind de sfinți și personaje biblice. Comparația avea în vedere țările catolice, în special Franța și Spania, unde toponimia hagiografică „are o amploare extraordinară, reușind să se impună, în evul mediu, ca tipul de creație toponimică dominant" (Moldovanu 1993: 109).

La noi, hagiotoponimia este bine reprezentată în Transilvania și Banat - mai ales printre secui, aşadar în județele Mureș, Harghita şi Covasna (Goicu 1999: 143). Iată câteva dintre localitățile care poartă un nume de sfânt (de obicei al celui care patronează biserica din aşezarea respectivă): Sânandrei din județul Timiş, Sântandrei din Hunedoara (Goicu 1999: 134), Sântion din Bihor, Sântioana în județele Bistrița-Năsăud și Cluj (Goicu 1999: 142), dar și oiconimul Sânzieni (Covasna), știut fiind că numele sărbătorii invocate provine din sintagma latinească sanctus dies Johannis (Goicu 1999: 122 123), Sânnicoară, în Cluj și Bistrița-Năsăud și Sânnicolau Mare în Timiș (Goicu 1999: 130), Sânpetru în Hunedoara și Braşov, Sânpetru Almașului în Cluj, Sânpetru de Câmpie în Mureș (Goicu 1999: 125), Sângeorz-Băi în Bistrița-Năsăud, Sângeorgiu (de Mureș) și Sângeorge în Banat (Goicu 1999: 120-121), Sânmartin în Bihor (Goicu 1999: 187), Sânpaul în Cluj (Goicu 1999: 187), Sântana în Arad (Goicu 1999: 187), Sânta Maria în Cluj, Sântămăria de Piatră și Sântămăria-Orlea în Hunedoara (Goicu 1999: 126) etc.

Cele câteva oiconime exemplificatoare de mai sus reliefează și particularitatea compunerii cu varianta sân a apelativul sânt (< lat. sanctus), care rămâne specific Vechiului Regat.

În Moldova (de pe teritoriul actual al României), toponimia hagiografică este slab reprezentată. În seria hagionimelor enumerate mai înainte se încadrează oiconimul Sânta Maria, numele unei localități din județul Botoșani, format după hramul bisericii din sat, Nașterea Maicii Domnului (MDTM 2014: 363); astăzi, în urma impunerii pe cale administrativă a unei deformări grafice, denumirea a ajuns la forma Santa Mare. Menționăm, de asemenea, Onofreiul, localitate numită după sfântul Onofrei, patron al mănăstirii din zonă (MDTM 2014: 295), și Sfântul Ilie, localitate botezată după hramul bisericii mănăstirii omonime (MDTM 2014: 371-372).

După cunoștința noastră, singura localitate din Moldova numită după un sfânt care să nu fie în legătură cu hramul unei biserici de acolo este $A d j u d u l$, a cărei denumire provine de la magh. Egyd < Egyed „Sanctus Aegidius” (Drăganu 1933: 466); oiconimul, rezultat prin reducerea la determinant a compusului maghiar Egydhalma („Dâmbul lui 
Egyd”), este martor al expansiunii secuiești în sudul Moldovei la începutul secolului al XIII-lea (MDTM 2014: 2-3).

Din timpul ocupației habsburgice a Bucovinei datează numele de factură creștină ale coloniilor înființate pe teritoriul satelor românești Iacobești și Țibeni, anume Fogodisten (<magh. Fogadj-Isten „Fie (bine) primit de Dumnezeu”), respectiv Istensegits (< magh. Isten-szegits „Dumnezeu să vă ajute!”), denumiri prin care coloniștii invocau protecția divină (Prisacaru 2015: 85). De asemenea, Freudenthal, numele fostei colonii germane de pe teritoriul satului bucovinean Valea Stânii, tradus prin Valea Bucuriei, intră tot în sfera religioasă, deoarece forma a rezultat în urma unei asocieri paronimice cu etimonul de drept Frauenthal „Valea Doamnei”, adică „vallis Beatae Mariae Virginis” (MDTM 2014: 177).

Așadar, observăm că oiconimele de mai sus ori sunt stabilite arbitrar, pentru a preaslăvi un sfânt, ori sunt motivate de faptul că au preluat denumirea ecleziastică a unui lăcaș de cult situat în sau lângă localitatea desemnată. Sigur, multe localități au același nume cu al mănăstirilor sau schiturilor pe lângă care s-au format: lângă Mănăstirea Agapia Nouă a existat satul Mănăstirea Agapia (MDTM 2014: 4), lângă Mănăstirea Coşula s-a format Satul Mănăstirii Coșula, numit astăzi Coșula (MDTM 2014: 102), lângă Mănăstirea Hadâmbul, odinioară schit, s-a întemeieat satul Schitul Hadâmbului (MDTM 2014: 201) etc.

Reflexe ale vieții religioase a românilor regăsim și în alte oiconime. Dintre numeroasele exemple întâlnite în lucrări precum Toponimia românească a lui Iorgu Iordan, unde există un subcapitol intitulat Toponimice care vorbesc despre credințe, superstiţii și obiceiuri (Iordan 1963: 232-253), articolul deja amintit al lui Dragoș Moldovanu (1993), volumul Simonei Goicu (1999), extragem doar câteva care conțin nume de lăcaşuri sau obiecte de cult: Mănăstirea Humorului (Suceava), Mănăstirea Doamnei (Botoșani), Mănăstioara (Suceava), Mănăștiur (Timiș), Mănăștur (Arad), Mănășturel (Arad), Cloașterf (Mureș) ${ }^{1}$, Mitocul (sate în Vaslui, Botoșani), Mitocul Bălan (Neamț), Mitocul Dragomirnei (Suceava), Schitul Duca (Iași), Schitul Orășeni (Botoșani), numeroase oiconime Chilia, Chiliile și Crucea etc.

\section{Toponime minore}

În articolul Intre toponimie, folclor și arheologie, Mircea Homorodean arăta cum omul de rând își reprezintă mediul geografic în general în două direcții: una descriptivă, când toponimele relevă trăsături fizice marcante ale locurilor (muncel, picior, șes, pârâu, cheie etc.), și una explicativă, aici înscriindu-se și numele cu semnificații mitologice, care „fac dovada unor încercări de interpretare, de explicare a elementelor mediului geografic-fizic. Caracteristice unui stadiu cultural îndepărtat, puțin evoluat, explicațiile despre care e vorba constau, în fond, în interpretări pseudo-științifice, mitice” (Homorodean 1979: 34).

1 Etimonul este termenul german Kloster „mănăstire”; de asemenea, locul unei foste bărății franciscane din Câmpulung (Argeș) se numește Cloașterul (Goicu 1999: 171). 
Întâlnim reprezentate în toponimie elemente pozitive ale mentalului religios. De personaje biblice amintesc oronimele 12 Apostoli, desemnând un grup stâncos din Căliman, lângă satul Șarul Dornei, și Adam și Eva, numele unor munți gemeni de la Pojorâta, atestați inițial, la 1775 , ca Pietrele. Tradiția populară asociază metaforic aceste oronime cu ipostaze din Biblie ${ }^{2}$, însă Dragoș Moldovanu crede că cel puțin Adam și Eva, denumire atestată între 1780 și 1856 , „se explică $[\ldots]$ nu printr-o metaforă românească, ci ca o creație a coloniștilor germani” stabiliți în aceste locuri în timpul ocupației habsburgice a Bucovinei (Moldovanu 1993: 108). Obcina Raiului sau Culmea Raiului, ramificație a Obcinei Dreptul (județul Neamț), este explicată de localnici prin faptul că „aici au fost înmormântați soldați ruși pe timpul primului Război Mondial” (Tudose 2012: 104 și 200).

Unele microtoponime sunt legate de manifestări religioase. Astfel, Dealul Calvarului (din comuna Luizi-Călugăra, județul Bacău) a fost numit astfel pentru că „aici era punctul terminus al «Căii Crucii», care ducea de la Biserică până la capela din vârful acestul deal”3 (Butnaru 2009: 35).

Prezența crucilor, troițelor și a altor repere religioase de bun augur la marginea sau la intersecția unor drumuri, pe dealuri sau în oricare alte locuri este foarte generos reflectată în toponimie. De exemplu, numai în comuna Luizi-Călugăra am întâlnit $L a$ Trei Cruci (pentru că pe la aceste cruci se făceau procesiunile), Ulița la Cruce, cartierul Sfântul Anton (pentru că aici a fost ridicată, la începutul secolului al XX-lea, statuia Sfântului Anton), La Capela de pe Calvar, La Capela de pe Gherț, La Capela (de pe) Sinislău, Intersecția de la Cruce, La Crucea lui Anton Pal, La Mănăstirea de la Trei Cruci, La Mănăstirea Franciscană, Crucea lui Andor, Crucea Sărății și deja amintitul Dealul Calvarului (Butnaru 2009: 39). În satul Mărgineni (județul Bacău) am identificat toponimele La Trei Cruci și Drumul Crucii, La Grotă (unde este amplasată Grota Sfintei Fecioare) și $L a$ Capelă. Observăm că în satele unde predomină populația ortodoxă regăsim în general doar toponime de tipul $L a$ Cruce, La Troiţă, La Biserică, La Cimitir şi nume topice formate prin polarizare de la acestea, pe când în comunitățile predominant catolice apar și denumiri legate de specificul manifestărilor religioase.

Există, de asemenea, microtoponime care amintesc de existența, încă din vremuri de demult, a unor locuri și lăcașuri în care și-au dus viața călugări, măicuțe sau alți credincioși: Peștera Sfintei Teodora de la Sihla, Chilia lui Daniil Sihastrul, numeroase toponime

2 Despre stâncile numite 12 Apostoli, dispuse în cerc, se spune că ar fi fost descoperite de niște păstori, care le-au asemuit cu cei 12 apostoli stând la cina cea de taină (PRISACARU). Forma ciudată a munților Adam și Eva este explicată, popular, prin faptul că „Adam, sfădindu-se cu Eva pentru păcatul săvârșit și lovind-o, i-a rupt spinarea și pentru aceea este ea șoldită; pe când Eva lui i-a aruncat cu un bolovan, încât a rămas ghebos" (Elena Niculiță Voronca, apud Moldovanu 1993: 107).

3 Oronimul este atestat și în Chestionarul lui N. Densusianu de la 1893, cu forma Calvaria, specifică graiului ceangăiesc (din magh. kalvaria): „În această comună se află un deal cu numele Calvaria, pe care oamenii îl țin de sfânt și este o bisericuță zidită pe acest deal” (cf. Butnaru 2009: 35). 
Chilia, nume de schituri (Schitul Nifon, Schitul Pahomie), mănăstiri (Mănăstirea Agapia, Mănăstirea Agafton ș.a.).

Dacă regimul comunist nu încuraja deloc practicile religioase, după Revoluția din 1989 credința creștină s-a putut exprima liber, concretizându-se și în construirea a numeroase lăcaşuri de cult, troițe, dar și în botezarea unor locuri și căi de comunicație după numele unor sfinți, sărbători sau slujitori ai bisericii. Astfel, oarecum în spiritul denominației populare, spontane, unele străzi poartă numele bisericii/schitului situat în imediată apropiere: în oraşul Iași există, de exemplu, Strada Sfântul Andrei (după biserica Sfântul Apostol Andrei), Piața Sfântul Anton de Padova (după biserica Sfântul Anton de Padova), Strada Sfântul Atanasie (unde este biserica Sfinții Atanasie și Chiril), Piața și Pasajul Sfânta Vineri (amintind de existența în acea zonă, în secolele XIX-XX, a unei vechi mănăstiri cu hramul Sfânta Vineri sau Sfânta Paraschiva) ș.a.

Dar există din ce în ce mai multe străzi botezate de reprezentanți ai administrației după numele unor sfinți sau fețe bisericești: Aleea Sfântul Ioan Iacob Hozevitul, Strada Mitropolit Iosif Gheorghian, Strada Patriarh Teoctist Arăpașu, Strada Părintele Cleopa Ilie (în orașul Botoșani), Strada Mitropolit Varlaam (Timișoara), Strada Mitropolit Veniamin Costache (Constanța), Strada Mitropolit Firmilian (Craiova), Strada Sfântul Petru Movilă, Strada Mitropolit Iosif Naniescu, Strada Mitropolit Veniamin Costache (Iași). Fenomenul se întâlnește și la sate: Strada Preot Gheorghe Petz și Strada Preot Ioan Ferenț (în Butea, județul Iași), Strada Preot Munteanu Vasile, Strada Patriarh Nicodim Munteanu (în Pipirig, județul Neamț), Strada Preot Francisc Cojocea, Strada Preot Ioan Lucaci, Strada Preot Dumitru Adămuț (în Adjudeni, județul Neamț). Aceste hodonime sunt foarte lungi (fiind formate chiar din patru sau cinci termeni) și se dovedesc a fi dificil de folosit ca atare într-o comunicare informală. Anchete toponimice și sociolingvistice la fața locului ar arăta, probabil, că localnicii de acolo simplifică aceste sintagme denominative atunci când se referă la numele străzii unde locuiesc sau, la sate, folosesc alte denumiri, populare.

Există destul de multe locuri ale căror nume sunt rezultate în urma unui proces de analogie cu zone care ar fi stăpânite de personaje malefice. În ciuda credinței populare conform căreia pronunțarea numelui dracului ar avea drept consecință apariția acestuia, el este prezent totuşi destul de mult în formațiuni toponimice populare românești. Cel Rău „locuiește cu precădere prin bălți, lacuri și iazuri, apoi pe la mori, mai cu seamă pe la cele pustii, la răspântii, apoi prin păduri, râpi și alte locuri neumblate, case pustii, în pământ, mai ales unde sunt comori” (Bârlea 2014: 176).

Așadar, locuri înguste de pe traseul apelor repezi de munte, periculoase mai ales pentru cei care conduceau odinioară bărci sau plute, sunt considerate a fi stăpânite de Necuratul. Unele sunt numite Moara Dracului. În conștiința populară, moara este simbol al distrugerii, căci „moara tot dracul a făcut-o” (Niculiță-Voronca 1998: 22). Numai în zona Munților Bistriței am identificat mai multe locuri intitulate Moara Dracului: Cheile Moara Dracului (pe Pârâul Cheilor, afluent al Pârâului Valea Caselor ce se varsă în râul Moldova - Tudose 2012: 80), Moara Dracului (în Cheile Zugreni, pe Bistrița, „unde era tăt țanc și era numai o scară cu o funie, de trecut peste stânci” (Arvinte et al. 
1987: 73). Un afluent al pârâului Sărișorul Mare este numit Pârâul Moara Dracului pentru că , are o cădere de apă asemuită cu acea a unei mori de apă” (Tudose 2012: 272).

Unele cascade ale căror ape fac zgomot mare sunt asemuite tot cu mori stăpânite de Cel Rău: Cascada Moara Dracului, pe râul Bistrița (Nedelcu 1965: 7). De asemenea, locuri unde apele îşi schimbă brusc cursul, fiind periculoase pentru navigație, sunt considerate de popor ca fiind tot ale diavolului, căruia îi place să ia viețile oamenilor: Cotul Dracului pe Bistrița (Nedelcu 1965: $7^{4}$ ).

Analogia cu reprezentările iadului în imaginarul popular a condus la apariția mai multor toponime Gura Iadului; de exemplu, vulcanii noroioși de la Forocici sunt numiţi de localnici „gura iadului” (http://www.montaniarzi.ro/gura-iadului-sau-vulcanii-noroiosi-din-banat/), grotei de la Băile Apodor (județul Harghita) de pe Muntele Puturosul, unde se acumulează sulf și monoxid de carbon în concentrații foarte mari, încât riscul de a muri înăuntru este ridicat, i se spune tot Gura Iadului (https://www. efemeride.ro/baile-apodor-gura-iadului), iar câteva izvoare de apă minerală din Zimnicea au fost botezate tot Gura Iadului din cauza mirosului puternic de sulf (Iordan 1963: 249).

Legende populare încearcă să pună tot pe seama dracului existența unor stânci, a unor munți înalți, căci „piatra, munții [pe] cari îi vedem, dracul i-a făcut” (NiculițăVoronca 1998: $\left.25^{5}\right)$. De exemplu, Piatra Teiului, o stâncă înaltă de circa 20 de metri de pe fundul lacului de acumulare Izvorul Muntelui (în amonte de viaductul de la Poiana Largului), care se vede chiar și atunci când nivelul apei lacului este la cote maxime (v. Tudose 2012: 328-329), este numită și Piatra Dracului, iar oamenii din zonă au explicat prezența acesteia tot printr-o putere supranaturală malefică întruchipată de un căpcăun sau diavol, care a smuls stânca din Ceahlău și a prăvălit-o unde se vede și astăzi (cf. Tudose 2012: 328-329, Brill 2005: 632-633). Carul Dracului este o stâncă al cărei nume este sugestiv pentru dificultatea cu care se poate urca pe ea (Tudose 2012: 71).

Piatra şi nisipul sunt tot de diavol făcute, „pentru că îi era ciudă pe oameni, de ce nu-s ai lui, şi [...] s-a apucat să facă tot pământul piatră, să nu crească nimica, ca să n-aibă omul ce mânca" (Niculiță-Voronca 1998: 25). Așa, de exemplu, se explică de ce un deal de pe malul drept al Bistriței, format din pietre moi care se sfarmă (anchetă în satul Cut, județul Neamț) este numit Moara Dracilor. Tot cu o Moară a Dracilor sunt asemuite „curgerile de pietre din Piatra Argintăriei”, în satul Corbul, județul Harghita (Tudose 2012: 180).

Toponimul reflectă atitudinea denominatorului faţă de caracteristicile obiectului desemnat și în cazul următor: un loc unde apa Pârâului Secul dispare în subteran pentru circa $2 \mathrm{~km}$, pentru ca apoi să reapară, a fost numit Moara Dracului (Tudose 2012: 367); zgomotul produs de apa care curge în subteran „se aude la suprafață, ceea ce a înflăcărat imaginația localnicilor din zonă, care au pus fenomenul pe seama forței

4 Cf. Tudose (2012: 97-98): „Cotul Dracului. Schimbare bruscă de direcție a Bistriței la intrarea în defileul Toance, ceea ce crea mari probleme plutașilor de odinioară, de unde și atributivul «dracului» acordat acestui cot al râului”.

5 În alte legende, munții au fost creați de Dumnezeu (Niculiță-Voronca 1998: 25). 
supranaturale a răului” (Tudose 2012: 181). Și locuri întunecoase din păduri dese, greu accesibile, sunt considerate uneori a fi stăpânite de Cel Rău: Borta Dracului (în satul Borosoaia, județul Iași).

Pentru a preîntâmpina apariţia personajelor cu puteri nefaste, uneori oamenii evită să le pronunțe numele ${ }^{6}$ considerate de rău augur, înlocuindu-le cu eufemisme precum frumoasele, fetele, zânele, mândrele (Ioniță 1982: 85) sau muierile. Așa se explică toponime precum Vârvu Fetelor, Dâmbul Mândrei, Tâlva Zânei, Dealul Muierilor (Ioniță 1982: 85), Pietrele Muierilor (Arvinte et al. 1987: 66), care desemnează locuri rele, greu accesibile. Și Mircea Homorodean vorbește despre superstițiile populare conform cărora unele elemente geografice sunt în strânsă legătură cu puterea nefastă a ființelor imaginare (Homorodean 1980: 177) și prezintă mai multe denumiri de acest tip, printre care Zleamăn, Cheile Cornii (chei sălbatice; cornea „numele dracului), Minunatul sau Dâlma Minunatului, Pârâul Minunatului (unde minunat este eufemism pentru drac), Cetatea Fetei, Colțul Fetei (stâncă în Cheile Turzii), Gaura Fetei (numele unei peșteri, aflată lângă o altă peșteră numită Drăcoaia), Bolboana Fetelor (loc cu apă adâncă pe râul Hășdate).

Despre spații care creează frică, asemănate, în imaginația denominatorilor, cu locuri stăpânite „de personaje malefice, printre care și diavolul cu numeroasele lui numiri eufemistice” vorbește și Vasile Ioniță în lucrarea Nume de locuri din Banat, oferind spre exemplificare toponime precum Culmea Dracului, Pietrele Dracilor, Tău Dracului, Arătania, Dealul Hicleanului, Sotea (Ioniță 1982: 85). Și Iorgu Iordan inventariază numeroase astfel de nume topice în capitolul deja menționat din Toponimia românească: Vălceaua Gheenei, Dealul Strigoaia, Curătura Strigoiului, Rediul Burchii sau al Zmeului, Gaura Zmeului sau Gaura Dracului etc. (Iordan 1963: 249-251).

\section{Toponime aparent religioase}

Un aspect care nu trebuie neglijat este diferențierea între toponimele personale, formate de la nume de persoană $\breve{7}^{7}$ și toponimele descriptive, desemnând locuri cu caracteristici care au determinat locutorii să le atribuie unor personaje mitice pozitive sau negative.

De exemplu, oronimul Dealul lui Dumnezeu, din județul Iași, de la care și-a luat numele și satul din apropiere, a fost explicat fie printr-o metaforă („din cauza înălțimei sale, oamenii i-au dat numele de Dumnezeu”), fie printr-o legendă populară („într-o dimineață s-ar fi arătat o vedenie albă, pe care oamenii au luat-o drept Dumnezeu”). În realitate, însă, dealul poartă numele familiei de răzeși Dumnezeu (MDTM 2014, ...). Pârâul Dracului, numele unui afluent al râului Putna de lângă satul Pojorâta, a fost

\footnotetext{
6 „În toate timpurile și în toate țările, oamenii de rând sunt încredințați că e destul a vorbi de ceva spre a se înfățișa aievea, că rostind bunăoară numele necuratului, el se va arăta negreșit. De aici apoi tendința de a evita numele apelative ale ființelor rele, ale spiritelor vătămătoare, ale evenimentelor funeste, și a le înlocui cu tot atâtea eufemisme" (Șăineanu 1896: 70).

7 Chestiunea este abordată și de I. Pătruț (1980: 132-133), care pledează pentru funcția de antroponim ale unora dintre cuvintele Drac, Dracea, Ciortea.
} 
explicat prin faptul că este un pârâu care rupe malurile, cu multe strâmtori. Însă sintagma Pârâul lui Drah, atestată la 1856, indică cu exactitate etimonul hidronimului, anume numele lui Drach Selig, un proprietar neamț din Câmpulung (Moldovanu, 95; cf. Tudose 2012: 245). În cazul oronimului Răiuț, provenit de la un nume de persoană *Răieț cu baza în bulgarul Raĭo, apropierea de apelativul ' răiuț, diminutiv de la rai, a condus la soluții etimologice neverosimile. S-a spus că numele ar avea legătură cu „situația de «rai»" existentă pe acest munte, unde, deși la altitudine mare, cresc pomi și arbuști (nuci, migdali, piersici, viță de vie, trandafiri sălbatici și măceși), despre care „se știe că sunt mai plăpânzi”, iar înălțimea muntelui a sugerat explicația ca „loc [...] aproape, deci, de Dumnezeu" (MDTM 2014: 343). Satul Pogana (Vaslui) are la bază numele lui Nicoară Pogan (MDTM 2014: 329), dar Iorgu Iordan, necunoscând etimonul exact, îl încadrează în seria toponimelor „sociale” în baza asocierii cu apelativul pogan „urât, straşnic, grozav”, „sinonim afectiv al lui drac” (Iordan 1963: 249). Păşunea La Drăcosu de lângă fostul sat Mielușoaia (Suceava) nu trimite la niciun personaj malefic, ci este numită după porecla dată proprietarilor acestor fânațuri, oameni isteți și glumeți, numiți ,drăcoși” în zonă (informație obținută în anchetă).

De asemenea, trebuie deosebite toponimele formate de la termenul religios cruce, desemnând principalul simbol al credinței creștine, de numele de locuri care au în componență apelativul cruce cu sensul de „loc unde se întretaie două drumuri, intersecție”: La Crucile Drumului (Butnaru 2011: 104) sau oiconimul Crucea din județul Suceava, care nu are legătură cu obiectul de cult, ci desemnează confluența în formă de cruce dintre râul Bistrița şi doi afluenţi ai săi.

Denumirea muntelui Bogolin, aflat pe dreapta Bistriței moldovenești (județul Suceava), este explicată de Dumitru Tudose ca fiind „produsul imaginației anonimului din popor, care a văzut în versantul muntelui, ce urcă brusc spre cer, de pe fundul adânc şi îngust al defileului, un drum sau o cale spre Dumnezeu" (Tudose 2012: 56). Însă toponimul trebuie să fie unul personal, format de la un antroponim Bogolin (cf. sl. Bogulin - Iordan 1983: 69). Interesant este faptul că pârâul care izvorăște de sub acest munte este numit atât Pârâul Bogolinului, cât și Pârâul Moara Dracului (din cauza albiei foarte abrupte) (Tudose 2012: 272), iar ramificația muntelui Bogolin pe unde curge această apă se numește Piciorul Moara Dracului (Tudose 2012: 343).

Şi dintre denumirile pe care Iorgu Iordan le încadrează la toponime sociale, „care vorbesc despre credințe, superstiții și obiceiuri” (1963: 232), între care Dracul sau Valea Rea, Valea Dracilor, Drăcoaia, Drăceni, Drăcești, Benga, Coasta Bengăi, Bengeștii ș.a., unele sunt formate de la nume de persoană - este cu siguranță cazul oiconimelor Drăcești și Bengeștii; numai o documentare pe teren şi în arhive ar putea ajuta la stabilirea adevăratei etimologii ${ }^{8}$. Lingvistul precizează doar în cazul toponimelor Dracea, Dracea Albă, Dracea Mare și Dracea Mică, Valea Drăcei că există posibilitatea ca unele dintre ele să provină de la un antroponim (Iordan 1963: 247).

8 Asupra dificultății recunoașterii toponimelor cu valoare mitologică atrage atenția și M. Homorodean (1979: 35). 
Sigur, etimologia de factură religioasă rămâne o simplă posibilitate și în cazul unor toponime precum Piciorul Muierilor (ramificație a muntelui Lespezi, de pe dreapta Bistriței moldave) sau Dealul Rai de lângă satul Pojorâta, al cărui nume este explicat de localnici prin faptul că, fiind în apropierea vârfurilor Adam și Eva, amintite mai sus, „aici s-ar fi coborât Adam și Eva când au fost alungați din Rai” (Tudose 2012: 116).

Un alt exemplu de toponim doar aparent religios este La Biserica lui Bândă, care desemnează fosta casă de apă din satul Adjudeni (județul Neamț). Denumirea are, de fapt, o încărcătură ironică, deoarece Bândă era porecla unui sătean care nu avea obiceiul de a merge la biserică (Butnaru 2005: 199).

\section{Concluzii}

Scurta incursiune în toponimia românească creștină a avut menirea de a ilustra unele aspecte ale modului în care mentalul religios al poporului român se reflectă și în procesul denominației geografice. Analiza celor câteva toponime excerptate din diverse volume sau adunate în urma anchetelor de teren ne-a relevat vechimea și diversitatea denumirilor topice de factură religioasă. Încă din vremuri îndepărtate există denumiri de localități formate de la nume de sfinți sau de la lăcaşuri și obiecte de cult (mănăstiri, schituri, chilii, cruci etc.). Apoi, numeroase nume de dealuri, ape sau chiar străzi amintesc de personaje bisericești sau de practici religioase. Unele sunt motivate în raport cu referentul desemnat, însă altele sunt pur arbitrare (de exemplu, hodonimele stabilite de către reprezentanți ai administrației, prin care se dorește preaslăvirea unor fețe bisericești).

O parte însemnată a textului de față este dedicată numelor de locuri care, în imaginarul popular, ar fi stăpânite de personaje supranaturale. În conștiința denominatorilor, unele obiecte geografice au fost asociate, cel mai adesea în baza caracteristicilor fizice, fie cu locuri stăpânite de Cel Rău, cu adevărat infernale, fie cu spații „de rai”, guvernate de forțe benefice. În urma unor astfel de reprezentări, au rezultat numeroase toponime precum Moara Dracului, Piatra Dracului, Gura Iadului, Obcina Raiului. În cazul multor denumiri de acest tip trebuie făcută distincția între toponimele descriptive și cele formate de la nume de persoană (care sunt doar aparent religioase). Presiunea superstiției populare conform căreia pronunțarea numelui dracului conduce automat la apariția acestuia a determinat folosirea în structura unor toponime și a eufemismelor: Pietrele Muierilor, Vârvu Fetelor, Dâmbul Mândrei ș.a..

Având certitudinea că reflectarea mentalului religios în toponimia românească are mai multe fațete decât au putut fi surprinse în aceste pagini (avem în vedere mai ales o analiză sociolingvistică, pe care ne-o propunem într-un studiu ulterior), scopul demersului nostru a fost de a contribui, alături de alte studii similare, la configurarea acestui proces atât de complex și de fascinant. 


\section{Bibliografie}

Arvinte, V., St. Dumistrăcel, I.A. Florea, I. Nuță, A. Turculeț. 1987. Noul Atlas Lingvistic al României. Moldova şi Bucovina. Date despre localități şi informatori. Bucureşti: Editura Academiei.

Bârlea, O. 2014. Mică enciclopedie a poveştilor româneşti. Craiova: AIUS.

Brill, T. 2005. Tipologia legendei populare româneşti. 1. Legenda etiologică. Bucureşti: SAECULUM. I.O.

Butnaru, D. 2005. Toponimia satului Adjudeni. În Adjudeni. Şase veacuri de prezență catolică pe valea Siretului, Dănuț Doboş (coord.), 187-207. Iaşi: Editura Sapientia.

Butnaru, D. 2009. Toponimia. În Monografia comunei Luizi-Călugăra, A.-A. Ilieş (coord.), 29-44. Roman: Serafica.

Butnaru, D. 2011. Toponimia bazinului hidrografic al Neamţului. Iaşi: Alfa.

Butnaru, D. 2013. Toponimia satului Butea. În Butea. Monografie, D. Doboş, S. Văcaru, A. Coşa, D. Butnaru, P. Blaj şi C. Cadar. Iaşi: Presa Bună.

Drăganu, N. 1933. Românii în veacurile IX-XIV pe baza toponimiei şi a onomasticei. Bucureşti: Imprimeria Naţională.

Goicu, S. 1999. Termeni creştini în onomastica românească. Timişoara: Amphora.

Homorodean, M. 1979. Între toponimie, folclor şi arheologie. Cercetări de lingvistică XXIV (1): 33-38.

Homorodean, M. 1980. Vechea vatră a Sarmisegetusei în lumina toponimiei. Cluj-Napoca: Dacia. https://www.efemeride.ro/baile-apodor-gura-iadului (consultat la 27.08.2017)

http://www.montaniarzi.ro/gura-iadului-sau-vulcanii-noroiosi-din-banat/ (consultat la 27.08.2017)

Ioniță, V. 1982. Nume de locuri din Banat. Timişoara: Facla.

Iordan, I. 1963. Toponimia românească. Bucureşti: Editura Academiei.

Iordan, I. 1983. Dicționar al numelor de familie româneşti. Bucureşti: Editura Științifică şi Enciclopedică.

MDTM. 2014. Moldovanu, D., D. Butnaru, Moscal D, Prisacaru, A.-M., şi Cojocaru V. Mic dicționar toponimic al Moldovei (structural şi etimologic). Partea 1. Toponime personale. Iaşi: Editura Universității „Alexandru Ioan Cuza”.

Moldovanu, D. 1993. Motive creştine în toponimia Moldovei. Teologie şi viaţă. III (4-7): 84-110.

Nedelcu, C. 1965. O călătorie pe Bistrița, de la izvoare până la Bacău. București: Grafica nouă.

Niculiță-Voronca, E. 1998. Datinile şi credințele poporului român adunate şi aşezate în ordine mitologică. Iaşi: Polirom.

Pătruț, I. 1980. Onomastică românească. Bucureşti: Editura Ştiințifică şi Enciclopedică.

Prisacaru, A.-M. 2015. Toponimia românească din Bucovina habsburgică (actualele teritorii românești). Germanizare și reromânizare. Iași: Demiurg.

Şăineanu, L. 1896. Studii folclorice. Cercetări în domeniul literaturei populare. Bucureşti: Editura librăriei Socec\&Comp.

Tudose, D. 2012. Munții Bistriței. Toponimie. Iaşi: PIM. 